\title{
EDITORIAL
}

Adv Clin Exp Med 2014, 23, 6, 857-863

ISSN 1899-5276

(c) Copyright by Wroclaw Medical University

Marzena Dominiak ${ }^{1, A}$, D, Tomasz GedrangE ${ }^{1,2, E-F}$

\section{New Perspectives in the Diagnostic of Gingival Recession}

${ }^{1}$ Department of Oral Surgery, Wroclaw Medical University, Poland

${ }^{2}$ Department of Orthodontics, Technical University of Dresden, Germany

A - research concept and design; B - collection and/or assembly of data; C - data analysis and interpretation;

$\mathbf{D}$ - writing the article; $\mathbf{E}$ - critical revision of the article; $\mathbf{F}$ - final approval of article; $\mathbf{G}$ - other

\begin{abstract}
Gingival recession (GR) is a common clinical situation observed in patient populations regardless of their age and ethnicity. It has been estimated that over $60 \%$ of the human population has gingival recession. It is the final effect of the interaction of multiple etiological factors. Identification and definition of the range of influence is often not possible, with the result that new methods for testing and elimination of potential etiological factors are still being sought. The aim of this study is to present the etiopathogenesis of gingival recessions with regard to the analysis of morphological and functional factors. For the assessment of the bone factors, we will describe the new cephalometric method for measuring sagital width of the bone in the central incisors area, places when GR are most commonly observed. Also, a review will be presented of modern methods of treatment; in particular classes recessions; usage substitute of autogenous tissue will be emphasized - collagen matrix, and primary culture fibroblasts on collagen net (Adv Clin Exp Med 2014, 23, 6, 857-863).
\end{abstract}

Key words: gingival recession, aetiology, diagnostic, cephalometric analyses, incisors area.

An adequate width of attached gingiva is necessary to maintain a healthy periodontium, especially in orthodontics or restorative treatments in periodontics. The periodontium or mucogingival complex consists of free and attached gingiva, mucogingival junction (MGJ) and the alveolar mucosa $[1,2]$. The attached gingiva is defined as the tissue between the MGJ and the projection on the external gingival surface of the most apical portion of the gingival sulcus or periodontal pocket. The width of the attached gingiva is genetically predetermined and varies in different areas of the dentition, and its dimension can change throughout life [3]. The consequences of mucogingival problems could be, on the one hand, pocket formations, due to a close disruption of the complex. Otherwise, open disruption of the mucogingival complex results in gingival clefts and gingival recession [1]. A mucogingival problem is, then, defined as the presence of gingival inflammation and gingival recession in areas with little or no attached gingiva [3].

\section{Prevalence, Etiology and Classification of Gingival Recession}

Gingival recession is defined as the displacement of marginal periodontal tissues apically to the cemento-enamel junction $[3,4]$. This means that the marginal gingiva shifts from its normal position on the crown of the tooth to the levels on the root surface beyond the cement-enamel junction [2] (Fig. 1). The following consequences of gingival recession are known: tooth hypersensitivity, pain, caries and non-caries lesion, aesthetic distress, gingival bleeding, and plaque retention $[4,5]$.

Gingival recession is the final result of the impact of many etiological factors. The extent of the impact is often impossible to establish. Finding new and/or rating yet unknown factors and determining their impact is the essence of cognitive dental scientific research, especially in the context of high and ever-increasing incidence of gingival 


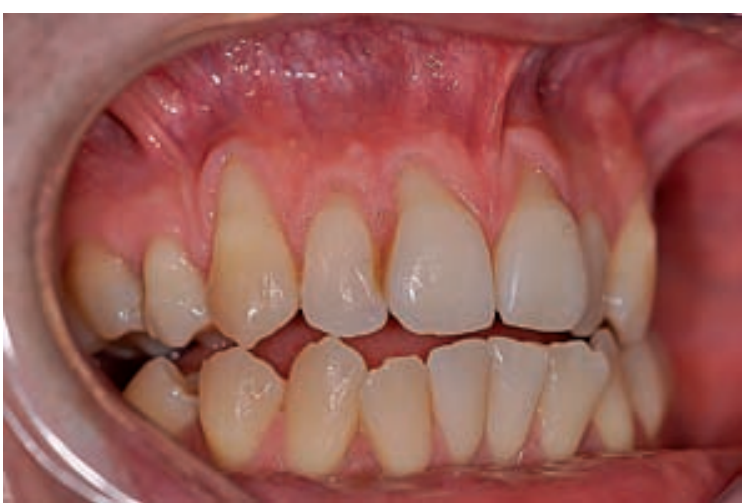

Fig. 1. Facial view of gingival recession on anterior maxillary right teeth

recession. Morphological factors play an important role in the development of recession. These factors in coexistence with other factors may give rise to changes in the mucogingival complex. Therefore, in today's classification, the following etiological factors are sub-classified in morphologic conditions (I) and driving forces (II-V) giving rise to gingival recession:

I. Primary morphological conditions

a) bone determinants - type of the alveolar bone (Class D1-D4 by Mish - ratio for cortical and cancellous bone), the anatomic structure of the mandibular symphysis, bone density, size and shape of the alveolar bone, b) mucous determinants - thickness of the keratinized gingiva, anatomy and position of the lip frenula, tongue frenulum and the buccinators muscle frenula, the depth of the oral cavity vestibule,

c) teeth determinants - shape and dimensions of the teeth, abnormal topography of the teeth (Fig. 2).

d) muscle determinants - strength and length of the muscle attachments, especially the mentalis muscle.

II. Functional factors

a) endogenic (primary):

1) oro-muscle dyskinesia, such as infantile swallowing pattern, the habits of the mentalis muscle,

2) occlusal and non-occlusal parafunctions,

3) posture disorders.

b) exogenic (secondary) - traumatic:

1) dental brushing (mechanical trauma),

2) centric and eccentric occlusion disorders (mechanical trauma),

3) iatrogenic damage during dental treatment (mechanical or chemical) (Figs 3, 4),

4) piercing (mechanical),

5) smoking (chemical).

III. Inflammation factors (secondary)

a) poor oral hygiene, b) periodontitis.

IV. Age, sex (secondary factors)

V. General diseases (secondary factors) $[6,7]$.

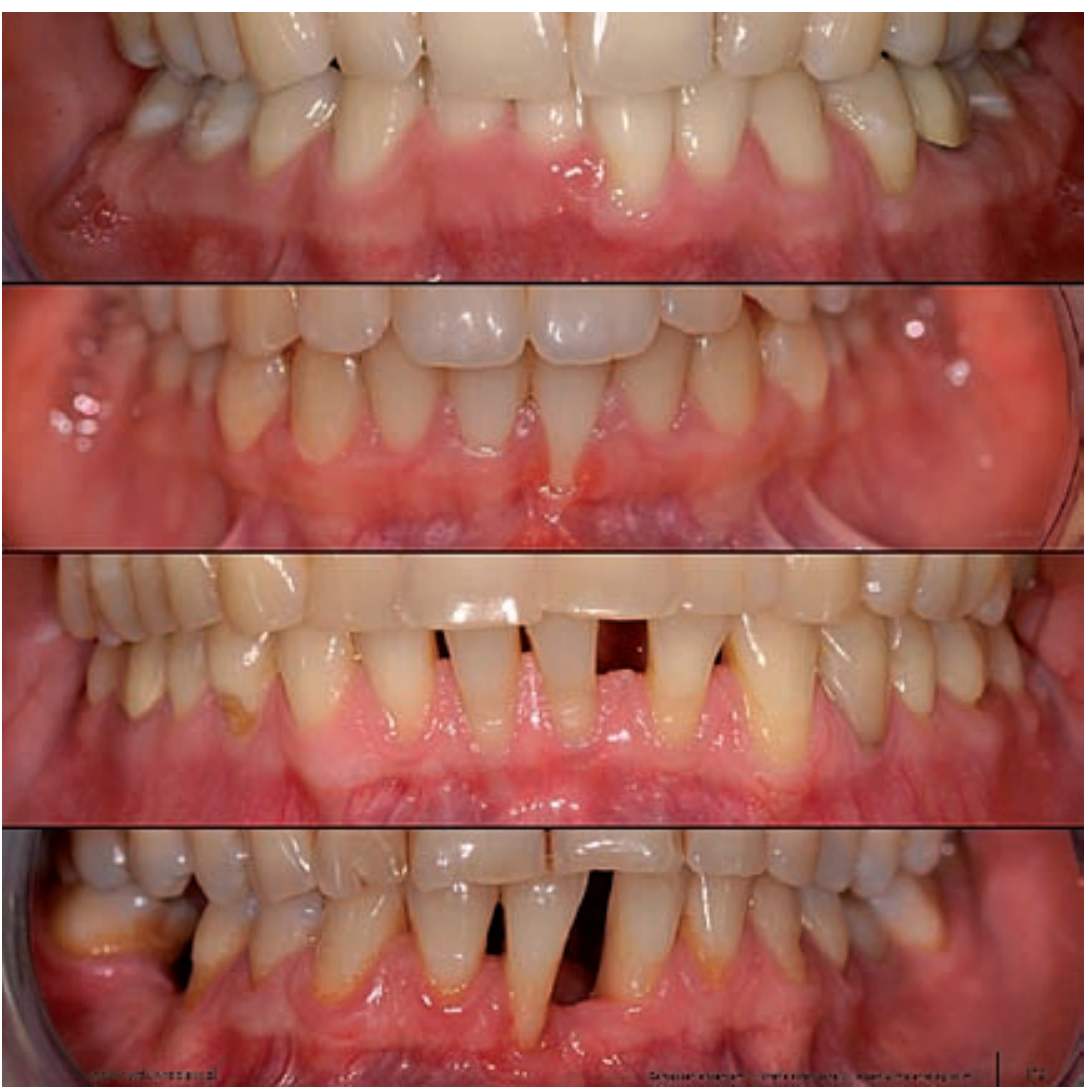

Fig. 2. Morphological Miller's classification of gingival recessions in four different classes [6] 
Gingival recession is a common clinical occurrence observed in patient populations regardless of their age and ethnicity. It has been estimated that over $60 \%$ of the human population has gingival recession [8]. Gingival recession was found in $64 \%$ of all tested subjects aged between 20 and 29 in Brazil. 99\% of the analyzed individuals older than 40 years showed displacements of marginal periodontal tissue in the same country. Furthermore, the increase in age led to an increase in the mean number of affected teeth $[9,10]$. The prevalence of gingival attachment loss in Pomerania, a province in Eastern Germany, was $89.7 \%$ in adults (20-81 years of age) with $62.8 \%$ of teeth

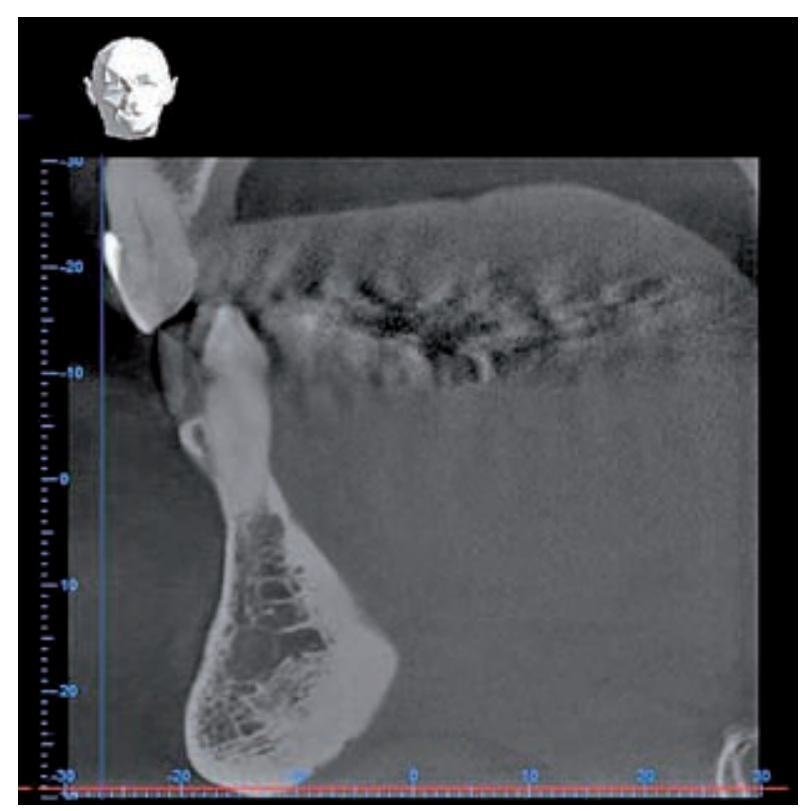

Fig. 3. Lateral X-rays of mandibular incisors reclined front teeth with normal bone level

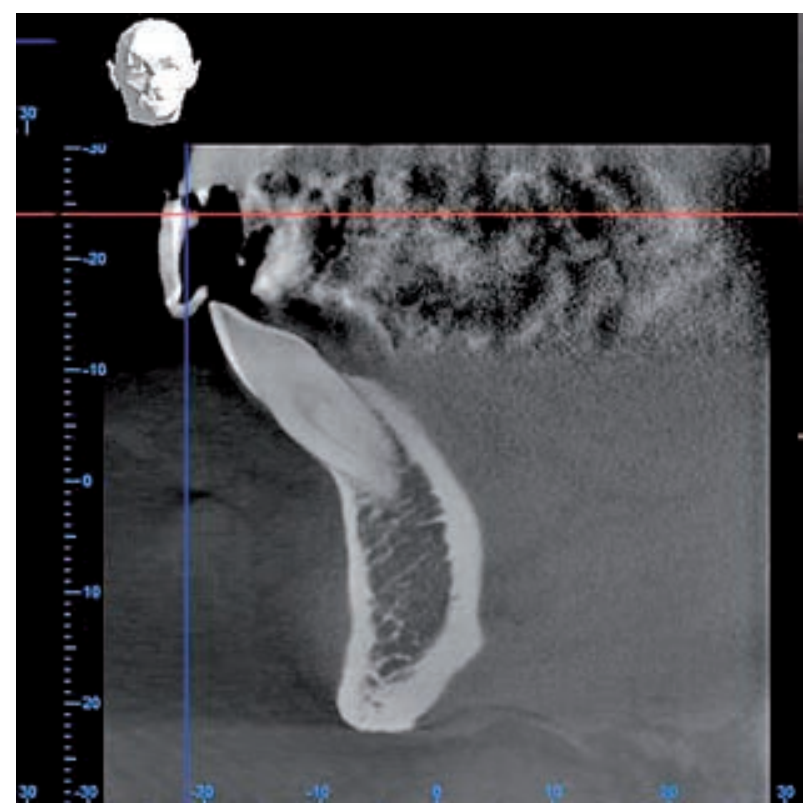

Fig. 4. Proclined front teeth with reduced alveolar bone being affected $[11,12]$. In contrast, in Norway only $51 \%$ of the adult subjects over 18 years of age had these defects [9]. This correlates with findings from Germany, where $50 \%$ of healthy young adults (19-30 years) presented gingival recession at one or more sites [13]. Interestingly, there was no significant difference in the prevalence of gingival recession between smokers and non-smokers [13]. Dodwad could show that 804 subjects out of 1200 tested subjects showed gingival defects in India. $67 \%$ of these patients were males and $33 \%$ females [1]. Furthermore, it was demonstrated that about $87 \%$ of these patients showed gingival recession in the mandibular anterior region [1]. This is in correlation with the findings from Marini et al. [10]. They showed that the mandibular teeth displayed more surfaces with gingival recession than the maxillary teeth and the mandibular incisors were the most affected teeth.

Similar trends were globally showed in epidemiological studies: i) gingival recession increases with age, ii) buccal surfaces are most commonly affected, iii) lower anterior teeth were more frequently affected and iv) men are more affected than women [4]. The severity of gingival recession can be classified using 2 different classification systems. Sullivan and Atkins categorized the gingival defects into deep-wide, shallow-wide, deep-narrow and shallow-narrow [14]. In contrast, the Miller classification categorized the defects into 4 classes (Fig. 2): class I (marginal tissue recession without extending to the mucogingival junction without bone and soft tissue loss in the interdental areas), Class II (marginal tissue recession extend to the mucogingival junction, but there is no loss of interproximal tissue), class III (marginal tissue recession extend to the mucogingival junction with loss of interproximal soft and bone tissue, secondary malposition teeth), and class IV (class III subsequently followed by severe tooth malposition) [15].

\section{Surgical Therapy of Gingival Recession}

Proper mucogingival therapy should lead to gingival augmentation and create a vestibule with adequate depth in the regions with insufficient attached gingival tissues. Several different techniques have been described in order to cover the exposed root surface, and increase the dimensions of the keratinized tissue in gingival recession defects ( $\mathrm{Ta}$ ble 1). Multiple gingival augmentation techniques with different success are described in the literature [16-19]. Generally, surgical techniques are used to cover recessions with different flaps-ex. rotational and lateral sliding as well as coronally 
Table 1. Methods of gingival recession treatment

\begin{tabular}{|c|c|}
\hline \multicolumn{2}{|c|}{ 1. PEDICLE FLAP } \\
\hline $\begin{array}{l}\text { Rotation flap } \\
\text { Laterally reposition flap } \\
\text { Double position flap }\end{array}$ & $\begin{array}{l}\text { coronally reposition flap } \\
\text { trapezoidal flap } \\
\text { semilunary flap } \\
\text { envelope flap }\end{array}$ \\
\hline \multicolumn{2}{|c|}{ 2. TUNEL TECHNIQUE } \\
\hline \multicolumn{2}{|c|}{ 3. FREE GINGIVAL GRAFTS } \\
\hline Full thickness grafts & connective tissue grafts \\
\hline \multicolumn{2}{|c|}{ 4. SOFT TISSUE SUBSITUTES } \\
\hline Allo- or kseno- dermal grafts & collagen, gelatin, fibrin or synthetic scaffolds \\
\hline \multicolumn{2}{|c|}{ 5. TISSUE ENGINEERING TECHNIQUE } \\
\hline \multicolumn{2}{|c|}{ 6. GUIDED TISSUE REGENERATION } \\
\hline Nonresorbable membrane & resorbable membrane \\
\hline \multicolumn{2}{|c|}{ 7. BIOLOGICALLY ACTIVE PROTEINS } \\
\hline Amelogenins & $\begin{array}{l}\text { polipeptyd growth factors } \\
\text { recombination growth factors }\end{array}$ \\
\hline
\end{tabular}

repositioned flaps or tunnel technique and to augment mucogingival defects, the free gingival autograft, the sub-epithelial connective tissue graft, and the acellular dermal matrix grafts $[5,20]$. The connective tissue graft in conjunction with a coronally advanced flap is the gold standard treatment for gingival recession defects [21].

Guided tissue regeneration-based root coverage is also one of the approaches for the treatment of gingival defects. This technique was first described by Pini Prato et al. [22]. In this study, results from patients treated with a surgical technique involving membranes were compared to those from patients undergoing mucogingival surgery (free gingival graft and a coronally positioned flap). It was found that the amount of root coverage was similar in both groups, whereas the clinical attachment gain and pocket variation differed significantly [22]. Saczko at al. described recently the isolation of primary fibroblast cells from connective tissue of oral cavity keratinized gingiva and setting on a collagenous carrier [23]. These scaffolds composed of primary fibroblast cells; isolated from connective tissue of the oral cavity keratinized gingiva and a collagenous membrane are effective for gingival augmentation, because recession depth and width was decreased. Furthermore, the height of the keratinized tissue was significantly increased. In addition, the post-procedure aesthetic increased in all cases compared to pre-procedure conditions [24] (Figs 5, 6). In addition, in a 6-month observation a significant decrease in the distance from cemento-enamel junction to

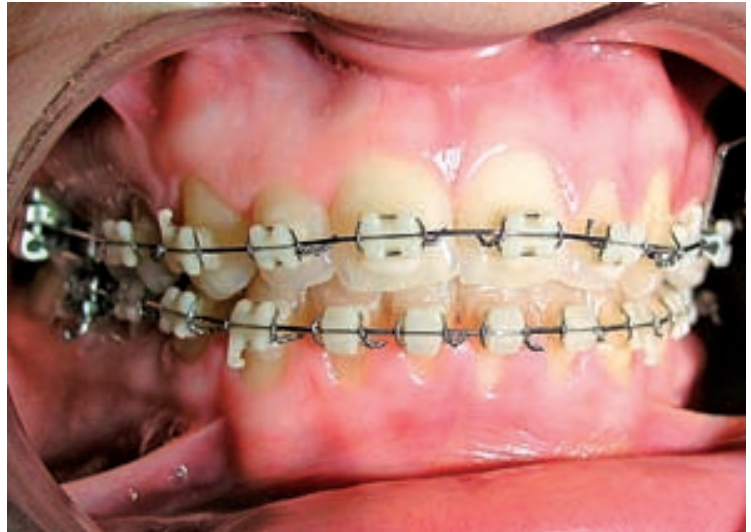

Fig. 5. Before surgical treatment

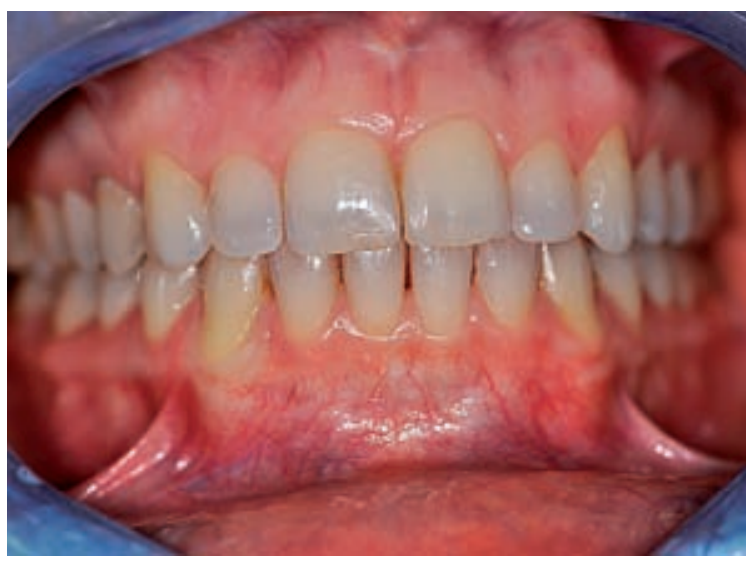

Fig. 6. Eight years post surgical evaluation of gingival recession after surgical treatment using scaffolds composed of primary fibroblast cells isolated from connective tissue of oral cavity keratinized gingiva and a collagenous membrane 
mucogingival junction was revealed. Histologically, mature connective tissue covered by keratinized epithelium was found after 12 weeks. No specimens revealed an inflammatory response. A complete clinical healing was observed after 2 weeks in 8 out of 10 patients [25]. This is in agreement with further studies using human gingival fibroblasts on a biodegradable collagen scaffold $[26,27]$. Using these scaffolds a significantly increased amount of attached gingiva at the test site compared to the control site was observed [26].

It is also possible to obtain root coverage without harvesting connective tissue. It was shown recently that Miller Class I and II recession defects can be treated with collagen matrix derived from porcine. A long junctional epithelial attachment as well as connective tissue adhesion was noted [21].

\section{Diagnosis of Gingival Recession}

The identification of gingival recession defects is essential, especially in prophylaxis/prevention as well as in dental treatment. Periodontal examination for mucogingival problems in Class I and II defects include measurements of gingival thickness and height, vestibular depth, the distance from cemento-enamel junction to gingival margin (recession depth) and from gingival margin to the mucogingival junction as well as bleeding index, and analyses of recession and inflammation. These studies evaluate a visible recession between the tooth and gingival edge from a clinical view. The second method is the hidden recession. It is covered by the gingiva area between the edge of the gingiva and the farthest point in the direction of the apex, in which the connective tissue trailers. The sum of "visible and invisible" recession matches the loss of connective tissue attachment to the tooth surface [28]. For the assessment of bone width dimension lip-linguistic methods are direct (invasive) and indirect (non-invasive like X-ray). The most important objective is to analyze X-ray images. Extensive use of cephalometric images in orthodontic diagnosis, however, did not result in the creation of many methods for assessing the alveolar width dimension between the tongue and lip in the anterior mandible. There are several limitations in the assessment of the alveolar, width dimension between lip and tongue. This method does not allow an accurate assessment of individual incisors as individual structures in the sagittal plane overlap. Because there is a large picture summation, difficulty in the interpretation of the various anatomical structures in this section appeared. In particular, it is difficult to identify the vestibular alveolar plate [29]. In addition, the resulting image is enlarged approximately $3.45 \%$, as compared with computed tomography, where the magnification is $1.2 \%$, representing almost 3-fold difference [30]. A semi-optimal method has been presented by Handelman [31]. Artun et al. also measured the width of the jaw in the cephalometric pictures [32]. These studies, however, were very inaccurate.

The construction of a finite element model from computer tomographic and micro-CT images is a suitable method for the analysis of osseous defects [33]. For the identification of Miller Class I and II recession defects, we established a simple method assessing the labial width of bone in the frontal area of the mandible in sagittal direction (angle API-CEJ2-B) and genial muscle width based on lateral X-rays in occlusion. On the model, the author's angle of bone labial width (CEJ2-B), genial muscle width and bone dehiscence height (CEJ2-B) were determined. Furthermore, measurements enabling the assessment of incisors location in alveolar process were made according to Ricketts, Björk and Steiner's cephalomeric analyses and, additionally, Holdaway's analysis (Figs 7, 8). Using this diagnostic method a significantly lower value of API-CEJ2-B angle and higher bone dehiscence was found in patients with gingival recession compared to that of healthy subjects. Furthermore, the angle of labial width of bone in the front part of mandible and the genial muscle width was significantly correlated to the height of CEJ2-B and line

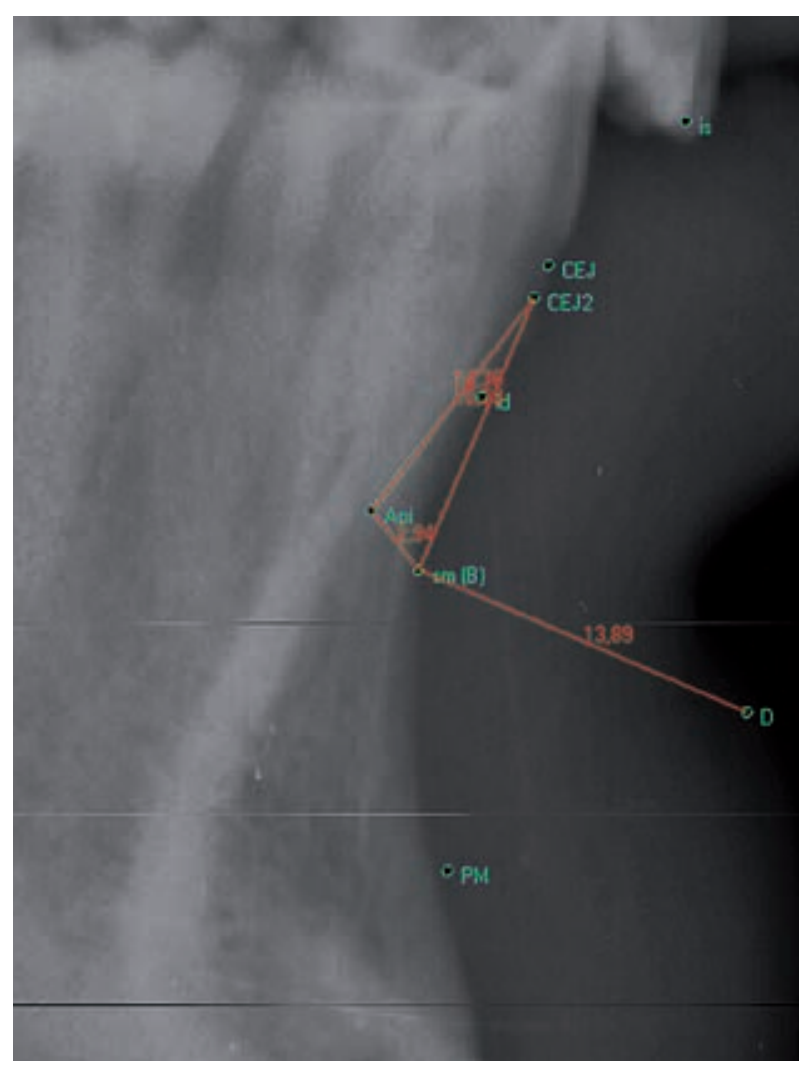

Fig. 7. Measurement on lateral X-rays in occlusion [7] 


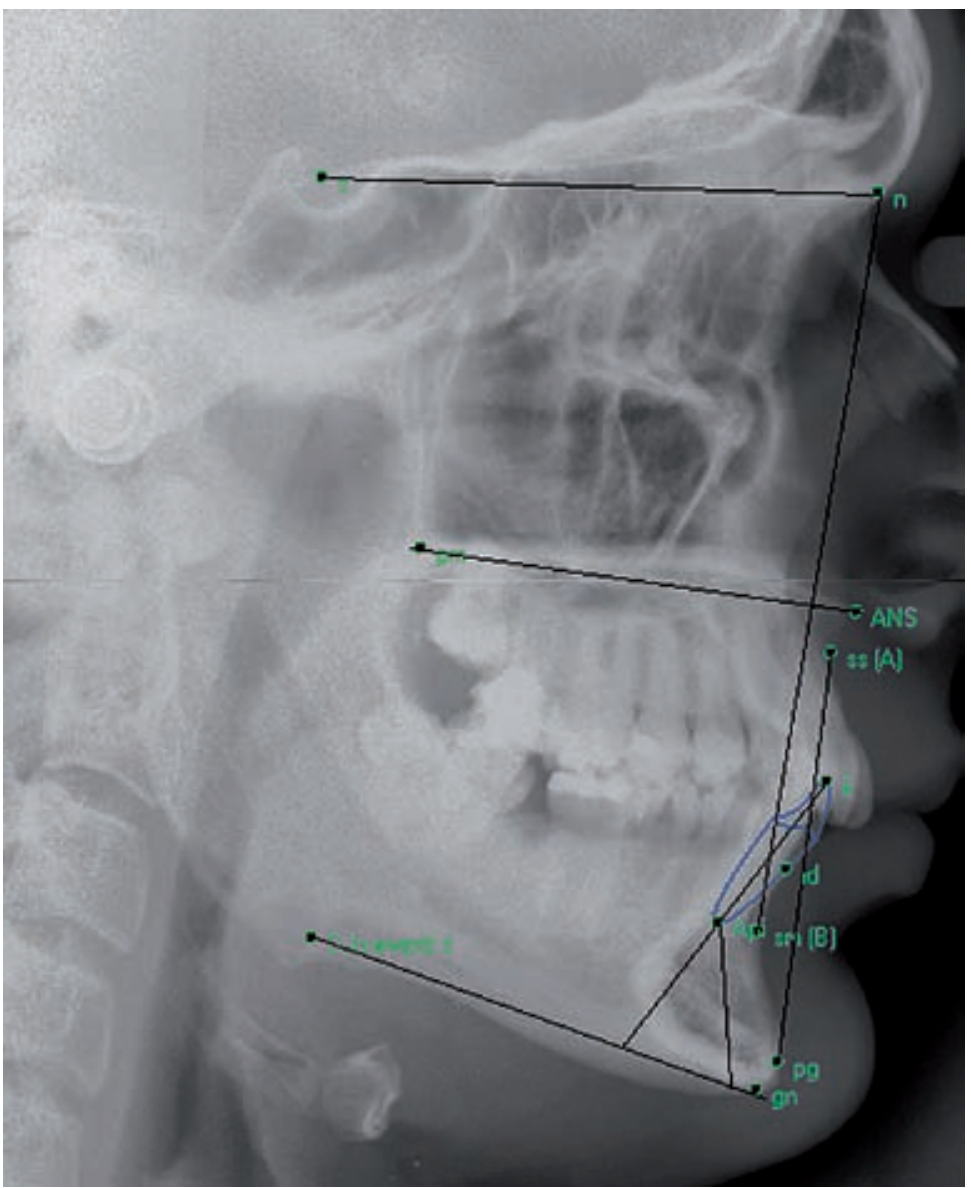

Fig. 8. Cephalomeric analyses of angle of bone labial width (CEJ2-B) and bone dehiscence height (CEJ2-B) on lateral X-rays in occlusion [7]

incisor proclination (ii/NBmm) in patients with gingival recession [7].

\section{Conclusion}

Taking into account the advantages and disadvantages of all indirect methods of assessing the width of the mandibular alveolar ridge dimension between tongue and lip and its relation to the roots of the incisors, it is clear that the CT method would be the best way to evaluate these structures. Due to the still limited availability of this method and the inability to assess the relationship of incisors to other craniofacial anatomical structures, the routine photo used for this purpose is still cephalometric X-ray.

\section{References}

[1] Dodwad V: Aetiology and severity of gingival recession among young individuals in belgaum district in India. Annal Dent Univ Malaya 2001, 8, 1-6.

[2] Leo H: Natural history of periodontal disease in man. J Periodontol 1992, 63, 489-495.

[3] Camargo PM, Melnick PR, Kenney EB: The use of free gingival grafts for aesthetic purposes. Periodontol 2000 2001, 27, 72-96.

[4] Wang HL, Modarressi M, Fu JH: Utilizing collagen membranes for guided tissue regeneration-based root coverage. Periodontol 2000 2012, 59, 140-157.

[5] Pradeep K, Rajababu P, Satyanarayana D, Sagar V: Gingival recession: review and strategies in treatment of recession. Case Rep Dent 2012, 563421.

[6] Dominiak M, Lula-Czarnecka K, Gedrange T: Interdisciplinary treatment in aesthetic zone in implantology. In: New indications in aesthetic implantology. Eds.: Dominiak M, Gedrange T, BF Remigiusz Dyńka, Wrocław 2012, 21-41.

[7] Dominiak M: Own method of estimation of prognostic gingival recession. Monography of habilitation, AM, Wroclaw 2010.

[8] Allen R: Treating gingival recession. Irish Dentist 2011, 20-26.

[9] Lauer G, Mai R, Pradel W, Proff P, Gedrange T, Beyer J: Influence of Cyclosporin A on human gingival keratinocytes in vitro. J Craniomaxillofac Surg 2006, 34, Suppl 2, 116-122.

[10] Marini MG, Greghi SL, Passanezi E, Sant'ana AC: Gingival recession: prevalence, extension and severity in adults. J Appl Oral Sci 2004, 12, 250-255. 
[11] Dominiak M, Kalecińska E, Krzysztoń E, Dominiak P, Mierzwa-Dudek D, Sulka A: Correlation between temporomandibular dysfunction, disturbances of occlusion and gingival recession in a group of youth students. Bull Group Int Rech Sci Stomatol Odontol 2006, 47, 40-46.

[12] Holtfreter B, Schwahn C, Biffar R, Kocher T: Epidemiology of periodontal diseases in the Study of Health in Pomerania. J Clin Periodontol 2009, 36, 114-123.

[13] Muller HP, Stadermann S, Heinecke A: Gingival recession in smokers and non-smokers with minimal periodontal disease. J Clin Periodontol 2002, 29, 129-136.

[14] Sullivan HC, Atkins JH: Free autogenous gingival grafts. 3. Utilization of grafts in the treatment of gingival recession. Periodontics 1968, 6, 152-160.

[15] Miller PD Jr: A classification of marginal tissue recession. Int J Periodontics Restorative Dent 1985, 5, 8-13.

[16] Camargo PM, Melnick PR, Kenney EB: The use of free gingival grafts for aesthetic purposes. Periodontol 2000 2001, 27, 72-96.

[17] Dominiak M, Konopka T, Lompart H, Kubasiewicz P: Comparative research concerning clinical efficiency of three surgical methods of periodontium recessions treatment in five-year observations. Adv Med Sci 2006, 51, Suppl 1, 18-25.

[18] Oates TW, Robinson M, Gunsolley JC: Surgical therapies for the treatment of gingival recession. A systematic review. Ann Periodontol 2003, 8, 303-320.

[19] Thoma DS, Benić GI, Zwahlen M, Hämmerle CH, Jung RE: A systematic review assessing soft tissue augmentation techniques. Clin Oral Implants Res 2009, 20, Suppl 4, 146-165.

[20] Dym H, Tagliareni JM: Surgical management of cosmetic mucogingival defects. Dent Clin North Am 2012, 56, 267-279.

[21] Camelo M, Nevins M, Nevins ML, Schupbach P, Kim DM: Treatment of gingival recession defects with xenogenic collagen matrix: a histologic report. Int J Periodontics Restorative Dent 2012, 32, 167-173.

[22] Pini Prato G, Tinti C, Vincenzi G, Magnani C, Cortellini P, Clauser C: Guided tissue regeneration versus mucogingival surgery in the treatment of human buccal gingival recession. J Periodontol 1992, 63, 919-928.

[23] Saczko J, Dominiak M, Kulbacka J, Chwiłkowska A, Krawczykowska H: A simple and established method of tissue culture of human gingival fibroblasts for gingival augmentation. Folia Histochem Cytobiol 2008, 46, 117-119.

[24] Dominiak M, Saczko J, Gerber H, Rybak Z, Gredes T: Use of primary culture of human fibroblasts in gingiva augmentation procedure. Biomed Tech 2010, 55, 331-334.

[25] Dominiak M, Łysiak-Drwal K, Saczko J, Kunert-Keil C, Gedrange T: The clinical efficacy of primary culture of human fibroblasts in gingival augmentation procedures - A preliminary report. Ann Anat 2012, 194, 502-507.

[26] Mohammadi M, Shokrgozar MA, Mofid R: Culture of human gingival fibroblasts on a biodegradable scaffold and evaluation of its effect on attached gingiva: a randomized, controlled pilot study. J Periodontol 2007, 78, 1897-1903.

[27] Dominiak M, Mierzwa D, Puzio M, Gedrange T: Clinical evaluation of the effectiveness of using a collagen matrix (Mucograft prototype) in gingival recession coverage - pilot study. J Stomatol 2012, 65, 184-197.

[28] Geiser EJ, Kleisner J, Marinello CP: Gingival recession. A review of its prevalence, etiology and classification. Schweiz Monatsschr Zahnmed 1993, 103, 1278-1287.

[29] Nauert K, Berg R: Evaluation of labio-lingual bony support of lower incisors in orthodontically untreated adults with the help of computed tomography. J Orofac Orthop 1999, 60, 321-334.

[30] Fuhrmann R: Three-dimensional interpretation of alveolar bone dehiscences. An anatomical-radiological study - Part I. J Orofac Orthop 1996, 57, 62-74.

[31] Handelman CS: The anterior alveolus: its importance in limiting orthodontic treatment and its influence on the occurrence of iatrogenic sequelae. Angle Orthod 1996, 66, 95-110.

[32] Artun J, Grobety D: Periodontal status of mandibular incisors after pronounced orthodontic advancement during adolescence: a follow-up evaluation. Am J Orthod Dentofacial Orthop 2001, 119, 2-10.

[33] Gedrange T, Mai R, Weingaertner J, Hietschold V, Bourauel C, Pradel W, Lauer G, Proff P: Finite element representation of bone substitute remodelling in the jaw bone. Biomed Tech 2008, 53, 220-223.

\section{Address for correspondence:}

Marzena Dominiak

Department of Oral Surgery

Wroclaw Medical University

Krakowska 26

50-425 Wrocław

Poland

Tel.: +48717840251

E-mail: marzena.dominiak@wp.pl

Conflict of interest: None declared

Received: 22.01 .2014

Revised: 24.04.2014

Accepted: 18.06.2014 